\title{
Connections: Superplasticity, Damascus Steels, Laminated Steels, and Carbon Dating
}

\author{
JEFFREY WADSWORTH ${ }^{1,2}$ \\ 1.-Battelle Memorial Institute, Columbus, OH 43201, USA. 2.—e-mail: wadsworthj@battelle.org
}

In this paper, a description is given of the connections that evolved from the initial development of a family of superplastic plain carbon steels that came to be known as Ultra-High Carbon Steels (UHCS). It was observed that their very high carbon contents were similar, if not identical, to those of Damascus steels. There followed a series of attempts to rediscover how the famous patterns found on Damascus steels blades were formed. At the same time, in order to improve the toughness at room temperature of the newly-developed UHCS, laminated composites were made of alternating layers of UHCS and mild steel (and subsequently other steels and other metals). This led to a study of ancient laminated composites, the motives for their manufacture, and the plausibility of some of the claims relating to the number of layers in the final blades. One apparently ancient laminated composite, recovered in 1837 from the great pyramid of Giza which was constructed in about 2750 B.C., stimulated a carbon dating study of ancient steels. The modern interest in "Bladesmithing" has connections back to many of these ancient weapons.

\section{BACKGROUND}

Although first discovered in 1912, the property of superplasticity only became heavily studied in the 1960 s. This was after the commercial potential of using superplasticity to replace expensive machining in $\mathrm{Ti}$ and $\mathrm{Al}$ alloys became of interest. By the mid-1970s, a race was underway to develop superplasticity in steels with a view to the potential commercial utility of such materials. In order to achieve superplasticity, it is necessary to develop a very fine grain size and to maintain that grain size during superplastic deformation. ${ }^{1-6}$ This is usually achieved by pinning the matrix grains with a finely dispersed second phase. For plain carbon steels, it was necessary to add far more carbon (about 1\% C or greater) than was available in most existing commercial compositions in order to prevent grain growth in a fine-grained ferrite matrix. The steels developed indeed demonstrated superplastic properties following appropriate thermomechanical treatments to develop the required ultrafine-grain structures for superplastic behavior. Early simple experiments, such as hot deformation of a range of carbon contents, illustrated fundamental issues such as the difficulty in going above about $2 \% \mathrm{C}$, as shown in Fig. 1. The carbon content range of the superplastic steels was from 1 to $2 \% \mathrm{C}$, and ultimately a family of compositions with some alloying elements was developed known as UltraHigh Carbon Steels (UHCS). ${ }^{7-11}$ Superplastic elongations in excess of $1000 \%$ were achieved, an example is shown in Fig. 2, and complex parts were superplastically formed from the steels but were never developed commercially to any significant degree although several steel companies cast them and processed them. ${ }^{12}$

As mentioned, minor alloying effects were explored, ${ }^{13-16}$ as was the role of thermal cycling. ${ }^{17}$ Additionally, the role of the divorced eutectoid transformation was examined and patented. ${ }^{18,19}$ Other high-carbon compositions were explored including white cast irons ${ }^{20-24}$ and tool steels..$^{25,26}$ Their heat treatment has also been the subject of historical as well as recent work. ${ }^{27-30}$

As described above, the desired structure for a superplastic material is one that is fine grained, typically less than $10 \mu \mathrm{m}$, and is stable at the superplastic-forming temperature which usually requires a second phase that is also of the scale of a few $\mu \mathrm{m}$. Ultimately, for the case of steel, a UHCS family of compositions was successfully selected and 


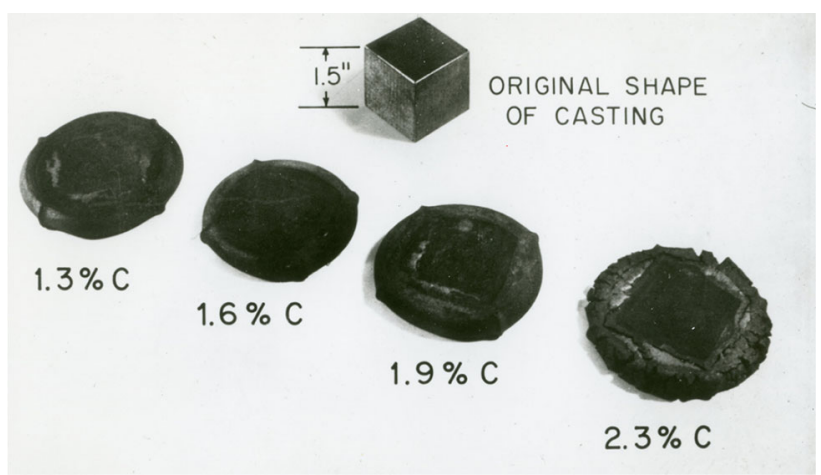

Fig. 1. Ultra-High Carbon Steel castings forged at $850^{\circ} \mathrm{C}$ in one step $(\varepsilon \cong 1.15$ ). The initial cube casting is about $37 \mathrm{~mm}$ on a side.

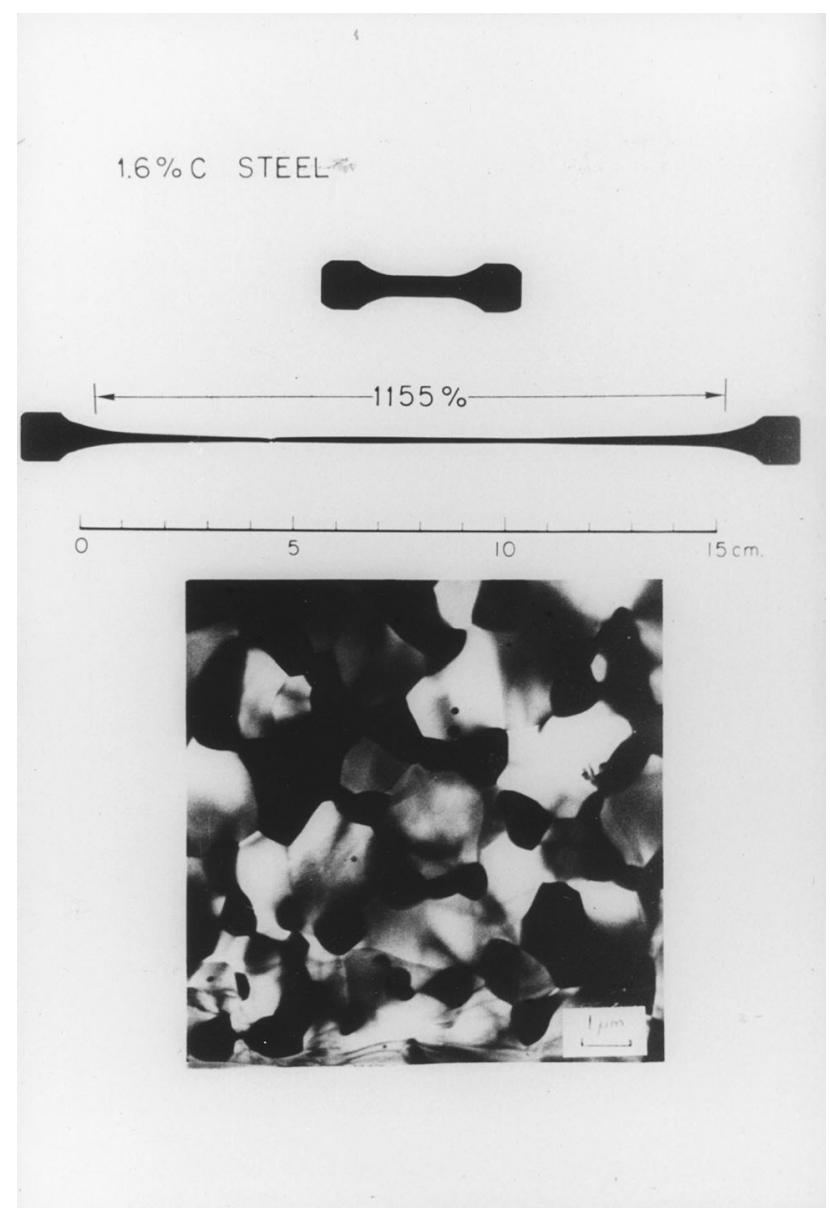

Fig. 2. A $1.6 \% \mathrm{C}$ UHCS superplastically deformed at $650^{\circ} \mathrm{C}$ to an elongation of $1155 \%$ with the TEM microstructure illustrating the fine ferrite grains (white) and the fine cementite particles (dark).

processed to have such structures. It should be noted that, when UHCS compositions are cooled from the melting temperature, the resulting room temperature structure consists of very coarse plates of pro-eutectoid cementite at prior austenite grain boundaries, and within these prior grains is a matrix of pearlite of eutectoid composition. This is clearly an undesirable structure for superplasticity, but also one that has very poor mechanical properties at room temperature which is one of the reasons such steel compositions had not been pursued in the past. With appropriate thermomechanical processing, it was possible to convert the structure to consist of ferrite grains, often of only 1-2 $\mu \mathrm{m}$, with a uniform dispersion of cementite particles that were $1 \mu \mathrm{m}$ or less. This structure was developed by first heating the steel to the single phase austenite phase and then deforming during cooling to below the $\mathrm{A}_{1}$ temperature. This was followed by extensive warm working to spheroidize and refine the carbides. In some cases, a divorced eutectoid step was added which involved thermal cycling just above and below the $\mathrm{A}_{1}$ temperature.

It was during the early stages of their studies of superplastic development in steels that Sherby and Wadsworth became interested in the similarity between the UHCS and their ancient counterparts. The ancient steels known as Damascus steels were also essentially plain carbon steels and had very similar carbon contents to those developed for superplasticity. An enormous amount has been written about the origins and processing of these steels. Much of this work has sought to understand the origin of unusual surface patterns associated with Damascus swords, daggers, shields, and other objects. ${ }^{31-37}$ An example of a Persian scimitar, from the author's collection, is shown in Fig. 3, and some of the details are highlighted. Famous scientists and metallurgists from the past have been associated with understanding how the surface patterns arose, perhaps the most famous being Michael Faraday who was the son of a blacksmith. Additionally, notable contributions were made from Russia (Anossoff, Belaiew), France (Bréant), and elsewhere.

The typical Damascus steel structure is related to the processed UHCS structure in that the matrix consists of ferrite with relatively fine carbides; it differs, however, in that the pro-eutectoid cementite is found in relatively coarse spheroidal form, in bands that are aggregated in such a way as to be visible to the naked eye after polishing and etching. An example is shown in Fig. 4 of a fragment of a Damascus steel and the associated microstructure. It can be argued that this is a less desirable structure than those found in the processed UHCS. This is because most modern theories on mechanical behavior would suggest that uniform, fine, second phases are optimal rather than a bimodal distribution. Of course, with a fine uniform distribution there would be no visible pattern and indeed some successful blades may well have had this structure. As discussed below, the precise origins of the patterns remain the subject of debate. This will not be repeated here, and the interested reader can review the literature for summaries of the issues. ${ }^{38-41}$ There are nonetheless some important points about which there is little disagreement. First, there is not a single type of Damascus 
(a)

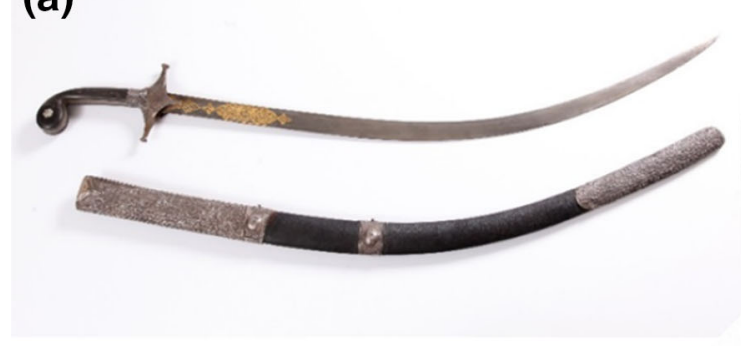

(b)

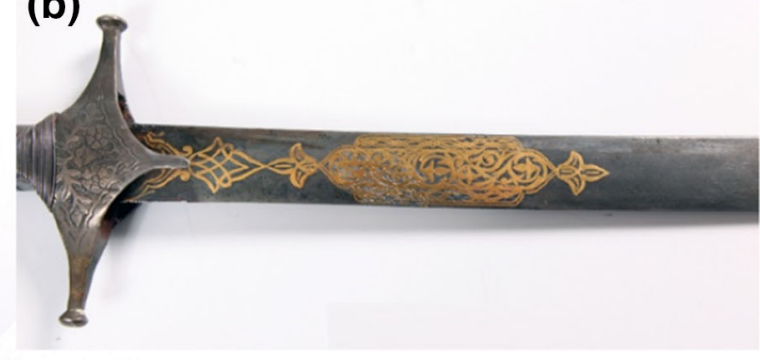

(d)

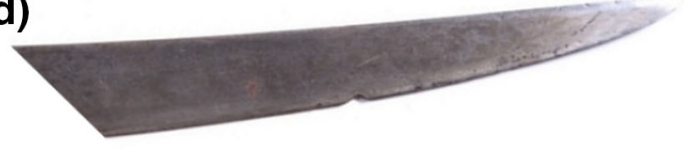

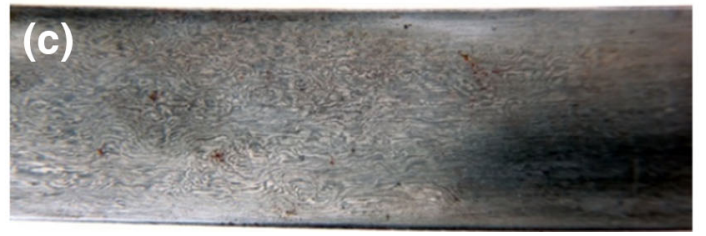

Fig. 3. A series of macrographs from a Persian scimitar are shown above. The sword in (a) is from the Wadsworth-Sherby collection and is believed to be from the seventeenth or eighteenth century but this has not been precisely determined. The features of the sword however are illustrative of swords from this era. The general curve and shape of the weapon, the style of the handle, and the gold engravings are characteristic. Looking more closely at the blade, there are a number of interesting details. The engravings from one side of the blade are shown in (b); their meaning is yet to be understood. In (c), a close up of the famous Damascus steel pattern is shown. At several locations on the cutting edge (d) are chipped areas presumably from use against other weapons. Research on this sword continues.

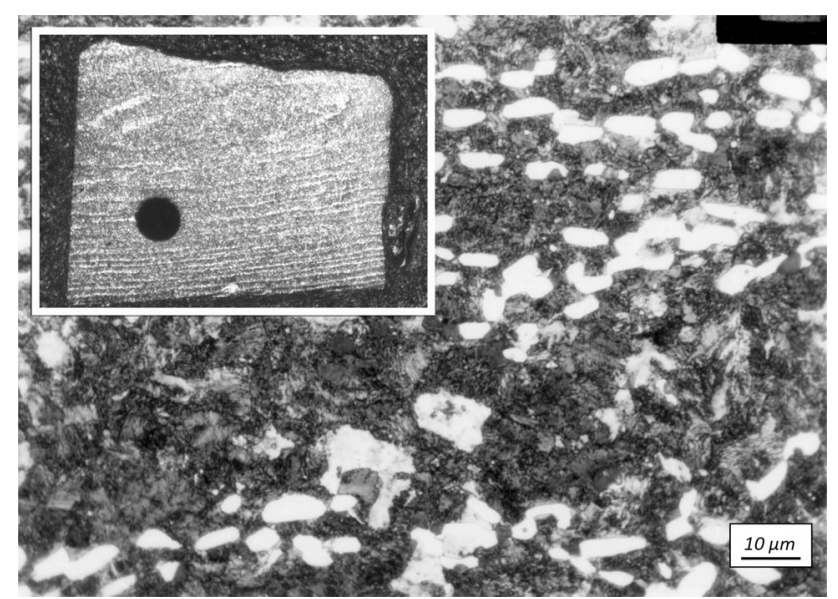

Fig. 4. A macrograph of a fragment from a Damascus blade (about $10 \mathrm{~mm}$ a side) showing the characteristic pattern. The microstructure reveals the mix of fine and coarse carbides; the latter carbides are aggregated and make the visible light-colored part of the macroscopic pattern.

pattern; there are many variations. However, in all genuine Damascus patterns (as opposed to patterns resulting from layered steels, etching, or engraving), the patterns arise from stringers of iron carbide particles that lead to visible differences from the matrix after etching as illustrated in Fig. 4. There is broad agreement about the spacing of the stringers (although they can certainly vary from very fine to coarse in the range visible to the naked eye). The approximate sizes of the relatively large carbides within the stringers or bands can and have been measured. ${ }^{31}$ Modern blacksmiths have been successful in reproducing the genuine Damascus steel patterns and they understand how to create some of the specialized features such as the so-called Mohamed's ladder. An example of a pattern developed at Stanford under work led by Sherby is shown in Fig. 5.

Although the UHCS families of steels were superplastic, and their room-temperature properties exhibited good combinations of strength and ductility, the impact toughness was not as good as hoped. For this reason, experiments were undertaken to see if lamination with other, tough, steels could improve the impact properties ${ }^{42-46}$ as well as other interesting mechanical aspects. ${ }^{47-49}$ This was indeed found to be the case. In a manner parallel to the case for monolithic Damascus steels, these results stimulated a study on laminated composites of steels developed over history. ${ }^{50-52}$ Ultimately, this study of ancient laminated composites included discussions surrounding the origins of the plate from the great pyramid of Giza ${ }^{53,54}$ about which there is disagreement. This in turn stimulated extensive carbon dating studies on a variety of ancient steel objects, ${ }^{5-59}$ although the Giza plate was not made available for carbon dating.

Examples of different patterns found on ancient blades of both the genuine Damascus and pattern welded variety are given in Fig. 6 (these blades in Fig. 6 are of museum quality) and in Fig. 7 for pattern-welded Indonesian krises.

In the following, some highlights from the previous studies described above are presented. Finally, although not given in detail here, there are some related topics such as the archeometallurgy of swords $^{60}$ and work on knives whose properties are 


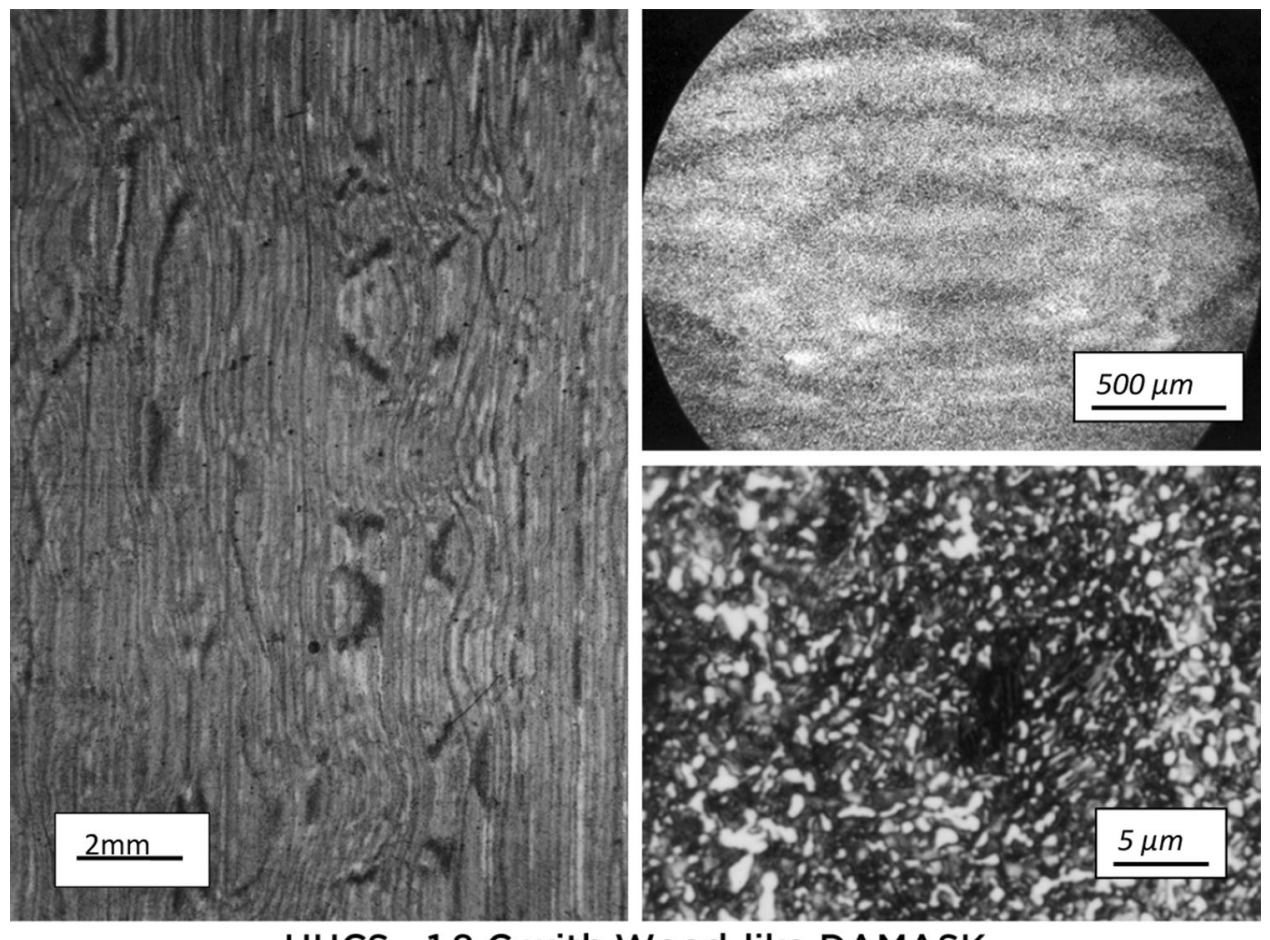

UHCS - $1.8 \mathrm{C}$ with Wood-like DAMASK

Fig. 5. Macrographs and micrographs of a 1.6\% C UHCS processed to produce a visible pattern. The microstructure reveals coarse carbides in bands that lead to the visible structure. These coarse carbides are finer than those shown in Fig. 4.

exceptional but whose processing history is shrouded in mystery, such as the knives of Frank Richtig. ${ }^{61}$

\section{DISCUSSION AND HIGHLIGHTS}

In a recent paper, the author wrote a tutorial on the archeometallurgy of swords. ${ }^{60}$ Some key themes from that work are described below. Archeometallurgy can be defined as the study of metal production and use by society. There is a subfield addressing the production and use of metals for swords. Swords can be of various lengths and shapes, may be curved or may be straight, and can have just a pointed end or also have one or two cutting edges. Swords are extensions from the work to produce knives and daggers as materials evolved. Their history spans millennia from the Bronze Age to the Iron Age. Swords were developed in similar time frames in many different cultures. Although materials used to make swords are commonly associated with metals, they have also been made from a diverse set of materials including wood, bone, and horn. In some examples, stone was used for short weapons and in others stone was incorporated into the cutting edges of wooden swords. As is the case in many examples of the evolution of materials and weapons, sword design evolved to meet new challenges in warfare; the development of cavalry techniques is such an example. It was not until the development and widespread use of firearms in the 1800s that sword development essentially stopped. Despite this practical matter, interest in swords remains extremely high for collectors of ancient weapons but also in modern games based on myths or imaginary worlds. From Excalibur to the Lightsaber of Darth Vader (or for modern fans of Star Wars, Luke Skywalker or Kylo Ren) there remains a fascination with the sword.

Apart from native copper and meteoric iron, the historical sequence of metal development evolved through pure copper, arsenic bronzes, tin bronzes, iron, and finally steel. Starting in the chalcolithic age, 4000-3500 B.C., there are the earliest examples of manufactured metals of smelted copper or arsenic bronzes. These are usually found in Anatolia or neighboring areas. The early Bronze Age (30002500 B.C.) sees the evolution of arsenic and antimony bronzes (it is noted though that tin bronze axes are found in Ur from 3500 to 3200 B.C.). Only short swords are found during these periods, the development of full length swords being limited by the strength of these early materials.

Swords developed from daggers; early metallic materials were relatively soft, and because of the ease of bending, long weapons were not practical. The first swords make their appearance in 1600-1200 B.C., that is, the late Bronze Age. Despite many detailed changes, for almost 3000 years the basic shape of a sword has not changed. Common features are a handle and a pommel, which can be either integrated or attached and which balances the weight of the 

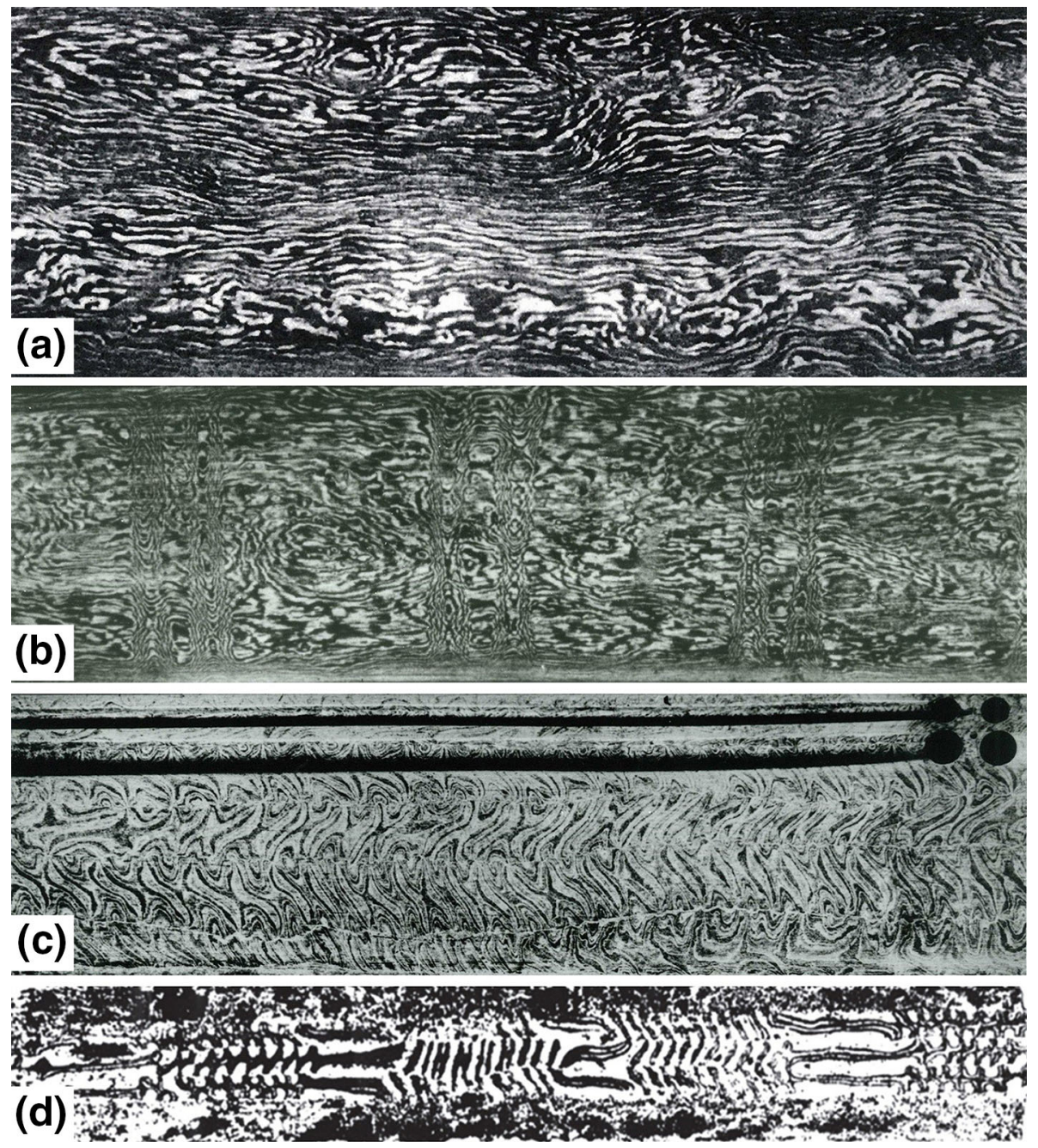

Fig. 6. Examples of different types of patterns found on swords; the widths of the blades are about $25 \mathrm{~mm}$. In (a) and (b), the patterns are the famous Damascus steel type which are visible to the naked eye. The patterns originate from the agglomeration of coarse carbides in bands and the matrix is of eutectoid composition. The typical wavy pattern associated with the swords is shown in (a), while in (b) is the special case of a "Mohammed's Ladder". In this case, the forging techniques lead to repeated vertical arrays of the bands. The blades are believed to be from the seventeenth or eighteenth century. (c) and (d) Two examples of patterns arising from solid state joining of different steels, i.e., pattern-welded blades. (c) A seventeenth century Chinese pattern-welded blade in which two steels of different composition have been hammer forged and folded. (d) An x-ray image of a Finnish blade, also called Merovingian, from 650 to 700 A.D. The pattern arises from low carbon steels that are twisted together and then enclosed in a folded steel casing. These blades when discovered are often imaged in situ using x-rays because they are usually heavily corroded. These photographs are shown through the courtesy of Dr. H. Nickel, Curator of Arms and Armor, Metropolitan Museum of Art, New York.

blade, and is connected to a blade through a guard. Grooves (or fullers) are often incorporated in the blade; without sacrificing key strength properties, grooves reduce weight.

It might be thought that, compared to tin bronzes, making iron should be relatively easy. This is because melting is not needed to manufacture iron; by contrast, three melting steps are required for hightin bronzes. However, transitioning from the Bronze Age to the Iron Age is recognized as a complex topic. For example, the earliest examples of iron manufacture are in fact similar in era to those of bronzes, but iron appears in far smaller quantities.

Ancient artefacts made from meteoric iron exist, but these are distinguished from man-made iron by their high nickel content as in the recent announcement regarding the blade of the iron dagger found on King Tutankhamun's mummy. Although smelted iron objects have been found from dates as early as 5000 B.C. in very small quantities (in Mesopotamia), rather than being deliberately made, these may be a by-product of copper smelting. From this date in other locations such as Egypt and Anatolia, additional objects have been found including some notable historical items. Nowadays, the start of the Iron Age is thought to be between 1200 B.C. and 1000 B.C.; however, this general statement does not cover considerable complexities including reasons for the unusually late development of iron making in Egypt (600 B.C.). The initial scarcity and hence value of iron led to its first use in ceremonial purposes. Because it was weaker than bronze, only 


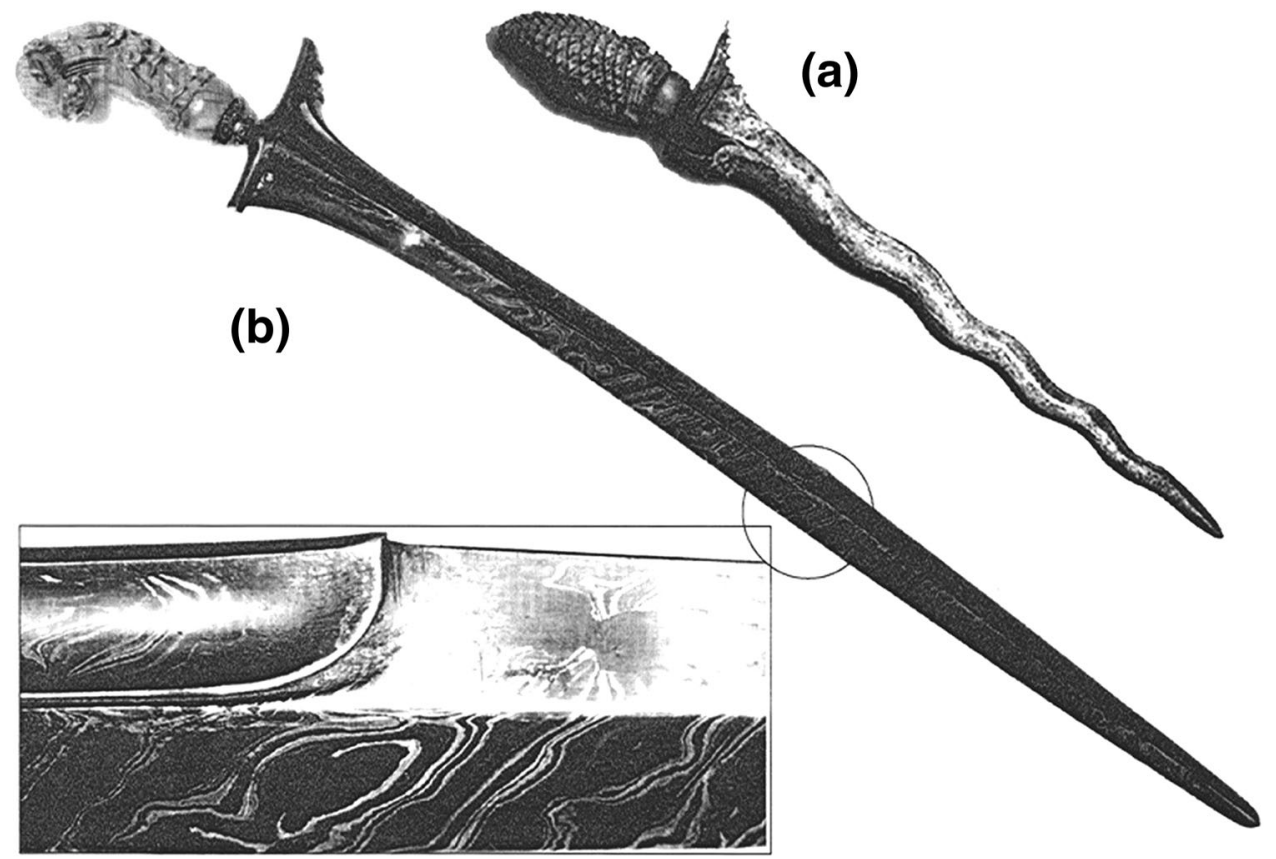

Fig. 7. Indonesian krises are pattern welded blades; they are often wavy as in (a) from the author's collection and the layers are a mixture of low and medium carbon steels. Occasional examples exist where the blades are straight as in the executioner's kris as in (b). In this latter case, the layers are plain carbon steel interlayered with Ni-rich meteoric iron sometimes called Pamir. The Ni-rich layers appear shiny and bright, contrasting with the plain carbon steel layers, after etching.

after the incorporation of carbon did it become useful as either a tool or a weapon. The relative strengths of bronzes and irons evolved with the carburization of iron, and the quenching of steels.

The driving force to develop iron and steel can be readily appreciated by considering the relative hardnesses of early metals and alloys:

Copper and early bronzes have a DPH (Diamond Pyramidal Hardness) of 50-70; to improve on this, features such as ribs for extra strength were incorporated into some Bronze Age swords.

Annealed wrought iron has a DPH of about 100 , similar to copper or bronze; through a cold working step, the DPH of wrought iron can be doubled to 200; these levels of DPH can be found for complex bronzes.

Carbon additions to iron of the levels found in Damascus swords dramatically improve the advantage over bronze; for example, an annealed Damascus sword of $1.5 \% \mathrm{C}$ has a DPH of 320-370.

Heat treatment has a profound impact, leading to values of DPH of up to 1000 .

Thus, as can be seen, increases of 10-20 times in hardness are found in steel over copper. Hardness is a useful surrogate for strength, although in the end ductility and toughness are also very important.

Steel swords and many knives can be catalogued into one of two basic groups. In the first, the starting point is a monolithic piece of steel; there are many such examples (including Damascus swords). The second group comprises swords and knives that are composites of two or more steels of differing carbon content. The initial pieces from which the sword is made are joined by solid state bonding at warm-tohigh temperature, usually by a forging process which may also include folding and twisting steps as well as other blacksmithing techniques to introduce surface features in the final patterns. The motives for this latter manufacturing process were sometimes driven by limited quantities of starting materials, such as in the making of early wrought iron. The bloomery process, of necessity, created thin strips which required lamination to form larger pieces. So, from the earliest times, hammer forging and folding have been utilized to form bulk laminated structures. Surface patterns, revealed after polishing and etching, led to the descriptor of "pattern-welded". Examples, shown in Figs. 6, 7, and 8, include early Merovingian blades, the Indonesian Kris, the Japanese sword, and some Chinese swords. (As might be imagined, the patterns of Damascus blades were construed by some observers to be the result of lamination of dissimilar materials.)

Taken from the author's review of swords, ${ }^{60}$ the following description of some aspects of the Japanese sword-making process is quoted verbatim: "The special area of the Japanese sword is one that has received enormous attention with many scholarly works as well as excellent publications available detailing the sword surfaces and shapes and 

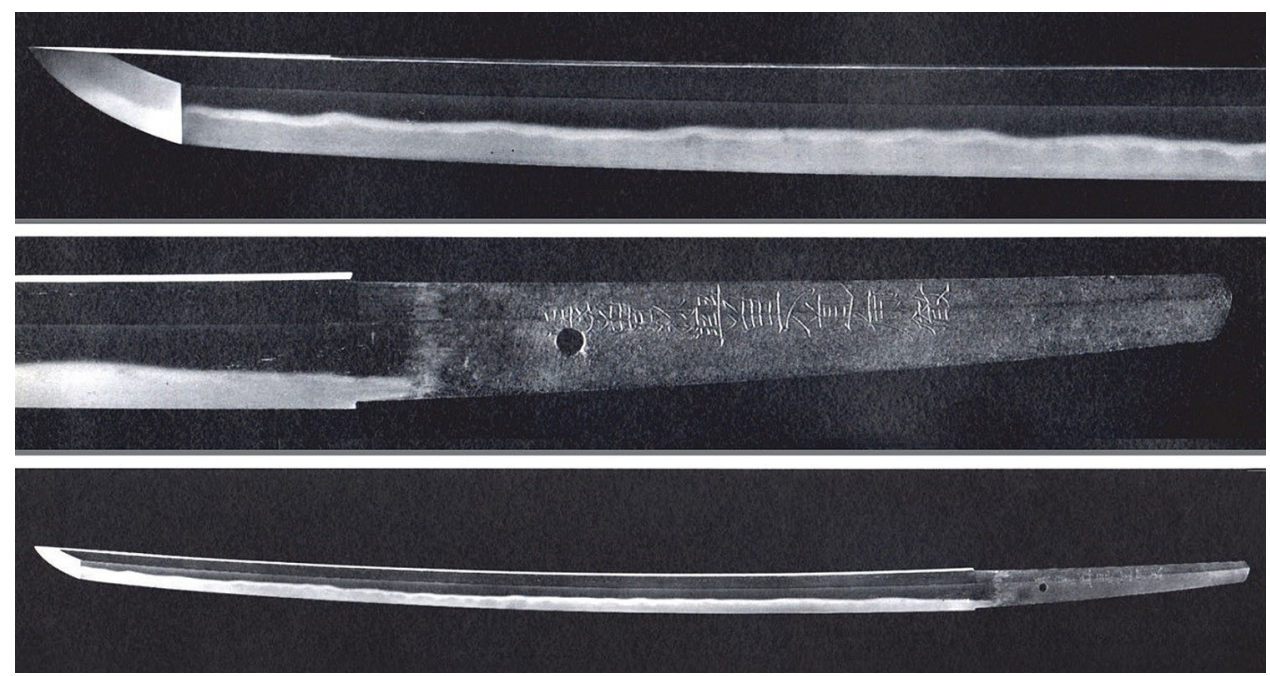

Fig. 8. A Japanese Katana from 1660 to 1670 A.D. The Japanese sword has a number of characteristic features that are evident to the naked eye but some that are not visible. There is usually a transformation zone consisting of martensite and bainite following quenching and this is visible at the edge of the blade. There is often an inscription on the tang as shown in the center, and the way the point of the blade is shaped and the beautiful arc the blade possesses are hallmarks from this period of Japanese swordmaking. Photograph of Tom Kishida, permission pending.

handles. It is believed that they evolved from Chinese swords such as the Jian, which had initially bronze and then steel forms. The Dao sword was exported to both Japan and Korea and influenced Japanese swordsmiths. Sword types evolved through the Heian, Kemakura, and Muramachi periods with the high point of Samurai sword making in the Kamakura period (1192-1333 A.D.). The swords are composites at several levels and have unique surface markings following heat treatment. The sword is essentially comprised of a high carbon (about 0.6-0.8\% C) sheath surrounding a soft low carbon steel core. The high carbon sheath is made by reducing iron ore with carbon in such a way as to produce very high carbon $(2 \% \mathrm{C})$ brittle pieces called tama-hagane that are then hammered together and repeatedly folded. This has the effect of reducing the carbon through repeated decarburization and also homogenizing the structure and refining it. The product at this stage is called kawagane and because of the repeated folding is often described as containing thousands of layers. However, work by the author and his colleagues demonstrated that discretion of individual layers is lost at about a thickness of a few microns, see Fig. 9. The high carbon outer sheath is folded around the soft core (shingane) and hammered into the final shape. Clay is then selectively arranged around the blade in such a way that the cutting edge is the only part containing transformation products following heat treatment and quenching. Following polishing, the surface of the sword contains patterns, sometimes extremely elaborate, on the cutting edge reflecting the different transformation zones. Occasionally the layers from the most recent of the folds in the outer layer can be seen. It has been pointed out that in many respects the Japanese sword structure is similar to the shear steel structure of Western Europe. The Toledo steel swords also consist of a high carbon sheath hot forged around a soft iron core and then quenched and tempered. Toledo steels have a long history dating back to pre-Roman times". An example of a Japanese Katana is shown in Fig. 8.

The study of ancient swords is confounded through history by accounts of the manufacture and properties of knives and swords interspersed with a mixture of facts and hyperbole. Some of the depictions in movies, often wildly inaccurate, are given in Ref. ${ }^{54}$. This shroud of secrecy pervades the recording of manufacturing details all the way from the starting steps of reducing ores to forging to sophisticated heat treatments. Some examples of the culture surrounding Japanese swordsmiths are available (see Ref. ${ }^{54}$ for detailed quotes) but for the essence of the difficulty in accessing details of manufacturing the following quotes are indicators.

In the 1973 documentary The Living Treasures of Japan, Akihira Miyairi states, "Remember, our work is not done by measuring and talking. The hammering, the forging, all the processes are performed by intuition ... I judge the temperature of the metal by eye ... this is all intuition. Experience, yes, repetition, trial and error; but it is kan (intuition), it is basically all kan. The flame, the color of the steel, the thickness of the clay ... I adjust these by kan. People say swordsmiths have secret formulas. I think it is kan, and this sort of thing can never be explained". Miyairi also disdains written records and explains that the "Old swordsmiths knew 


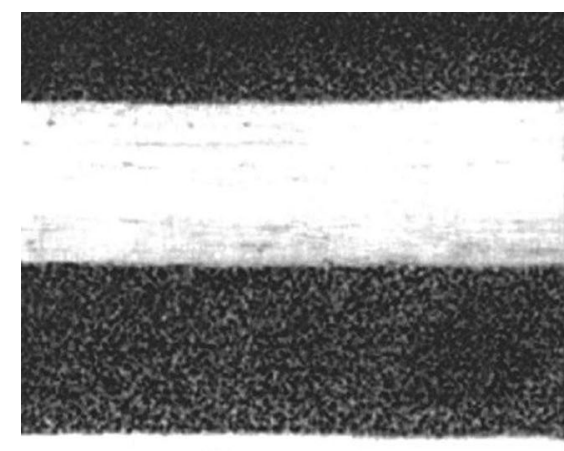

$\overline{100 \mu \mathrm{m}}$

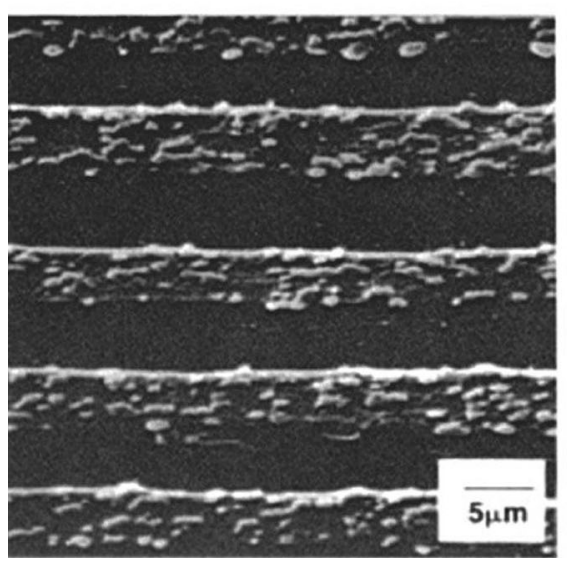

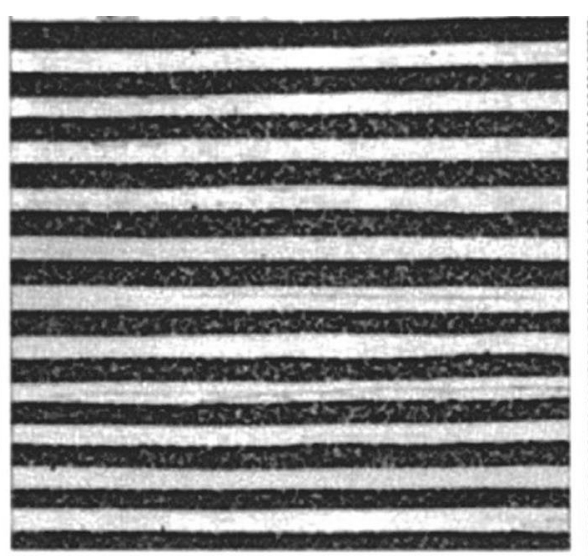
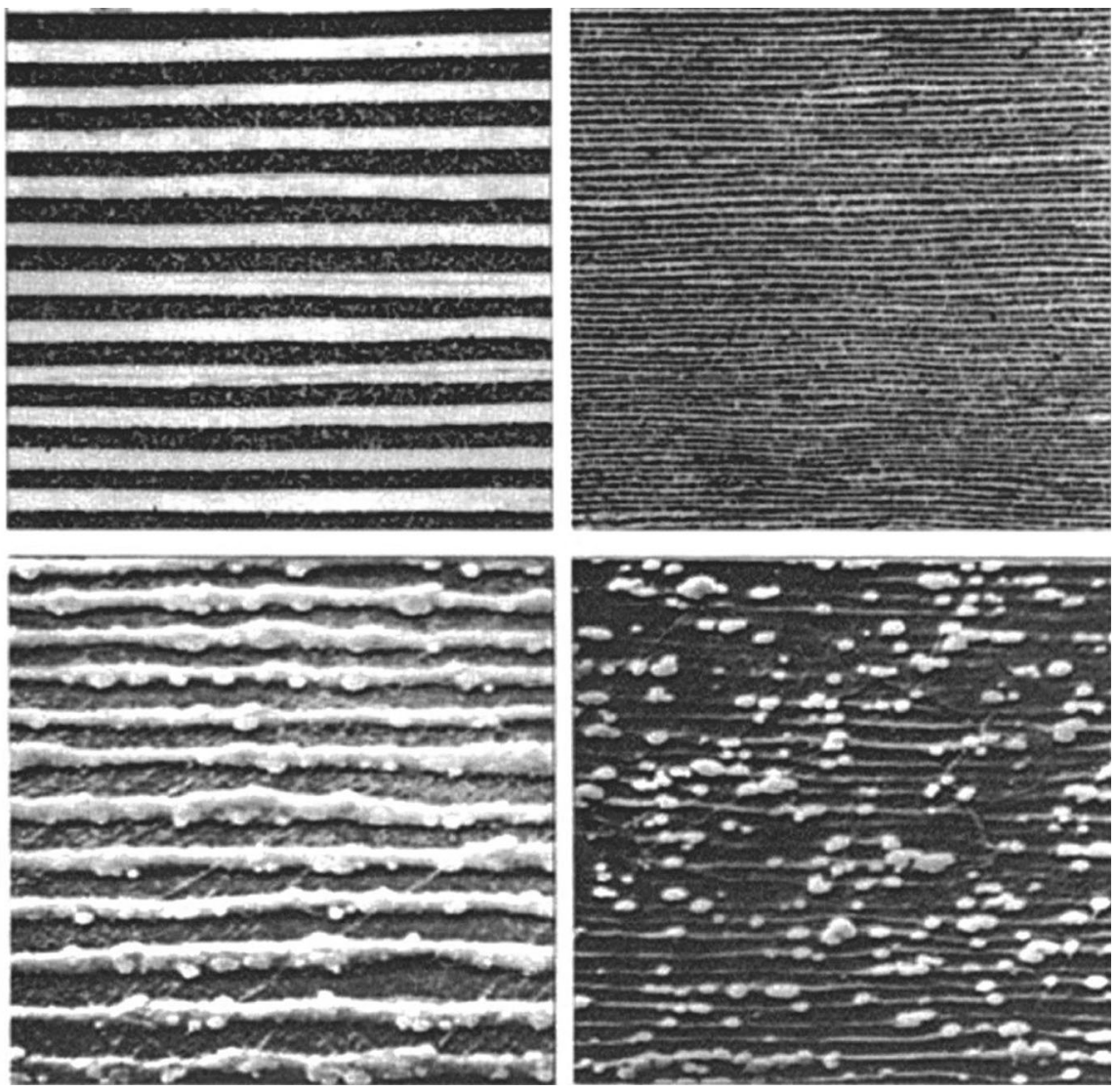

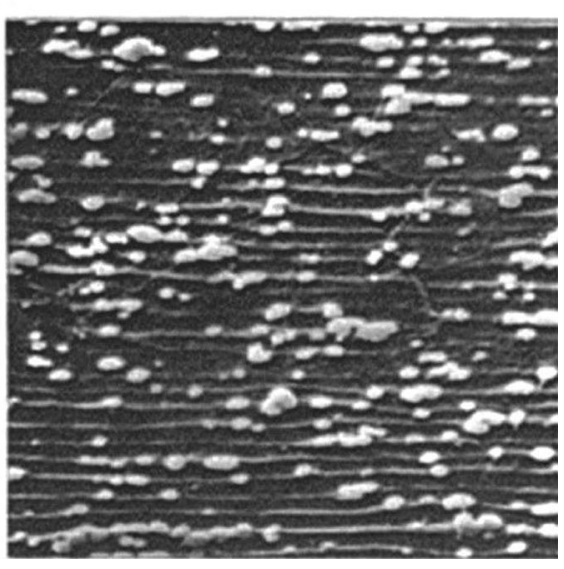

Fig. 9. To elucidate the real outcomes of multiple folding of two or more steels in the development of pattern-welded blades, experiments were carried out using laminates of alternating layers of $1.6 \% \mathrm{C}$ steel and $\mathrm{Fe}-3 \mathrm{Si}$ alloy. The $\mathrm{Fe}-3 \mathrm{Si}$ composition was chosen to minimize interdiffusion of carbon between layers to emphasize the discretion of layers. In the top row are light micrographs of samples processed to produce 25, 250, and 2500 individual layers. Scanning electron microscope photomicrographs are shown on the bottom row of the composite having 2500 layers after further processing to produce individual layer thicknesses of 5, 2, and $1 \mu \mathrm{m}$. Clearly, the carbides are uniformly distributed and individual layer discretion is lost at the $1 \mu \mathrm{m}$ thickness level. The loss of advantageous mechanical properties happens at much greater thicknesses in these types of layered structures.

where to go for good iron-rich river sand but they did not keep records. True craftsmen don't like to write things down ... and any of the ones that did keep records never produced a decent sword".

Relatively modern famous metallurgists such as Edgar Bain held the Japanese swordsmiths in the highest regard. In 1962, Bain wrote, "The old swords of Japan are probably the best examples of the almost incredible pains taken to produce a superb implement". Similarly, in 1960, Cyril Stanley Smith believed that the "Japanese sword blade is the supreme metallurgical art". Not everyone was quite so complimentary. In 1976, Tylecote stated that "There is essentially no difference in principle between a scythe (made from shear steel) and a Japanese sword".

If making swords from layered structures is indeed beneficial, the questions raised have to be: what is the mechanism, what is the optimal number of layers, and what is the nature of the interface between layers that allows for effective toughness improvements?
Experiments to understand the discretion of layers in laminated materials after repeated folding were carried out and the results are shown in Fig. 9. In this case, it can be seen that layer discretion is lost microstructurally at a $1 \mu \mathrm{m}$ level. An important topic is obviously the mechanical properties of layered materials. Figure 10 illustrates how the charpy v-notch toughness is improved beyond the properties of the component steels in a UHCS/mild steel laminated composite. Interestingly, if the interfaces are strengthened by heat treatment, the properties degrade.

The role of improved toughness through lamination is practiced commercially. For example, during a tour of a well-known welding facility in Kiev in 1993, the author observed the oil pipe shown in Fig. 11. The construction philosophy essentially consists of multiple layers of a wrapped thin layer of steel (rather like a roll of paper). The final layer is welded longitudinally and then adjoining sections are welded circumferentially to form a long pipe. The philosophy behind this design is to take 


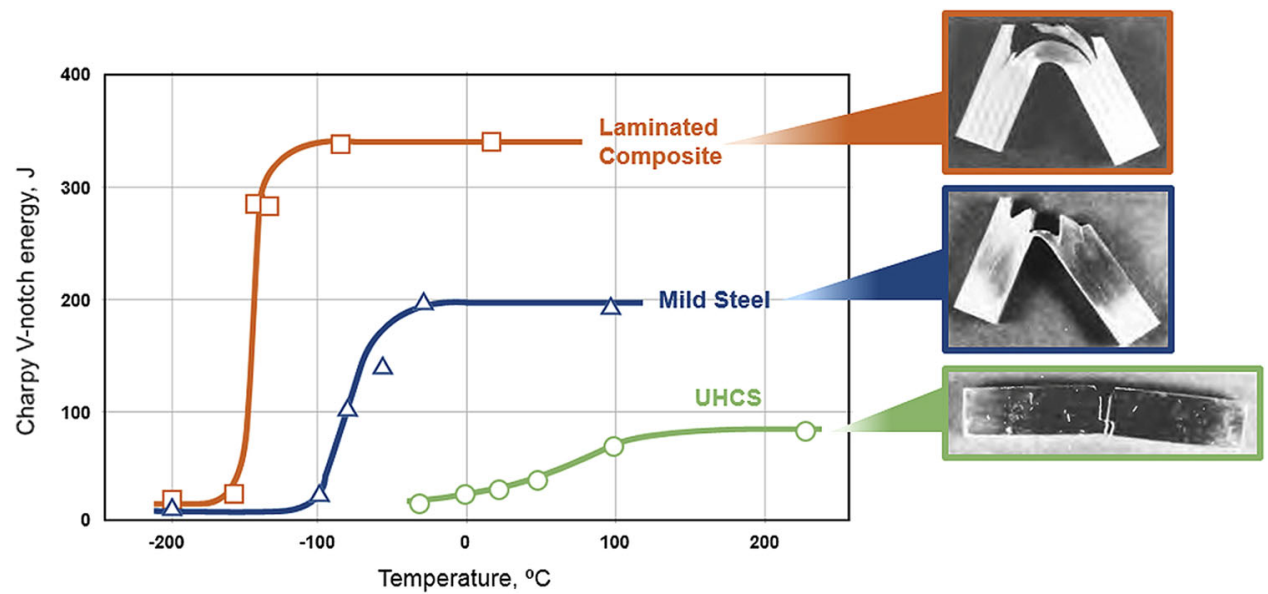

Fig. 10. The charpy V-notch impact properties are substantially improved in a laminated composite of UHCS and mild steel compared to the parent monolithic properties. In the accompanying photographs, the delamination associated with the increased energy absorption is evident.

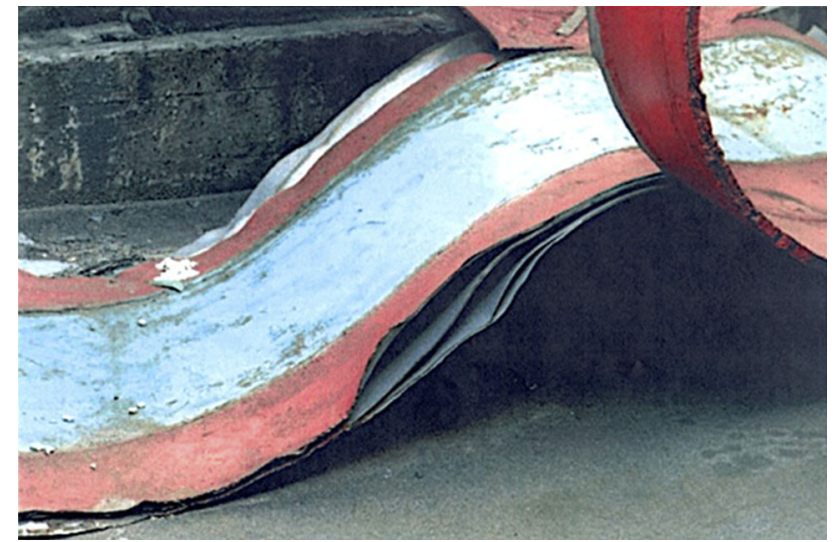

Fig. 11. A section from a Ukrainian oil pipe showing the laminated construction.

advantage of the high apparent $\mathrm{K}_{\mathrm{C}}$ of thin layered steel, accumulated by multiple layers, rather than build a thick walled steel to $\mathrm{K}_{1 \mathrm{C}}$ designs.

\section{Carbon Dating}

Establishing the date of origin of ancient artefacts is of great interest. Carbon dating $\left({ }^{14} \mathrm{C}\right)$ is the most appropriate isotopic method to establish those of iron-based objects. This is because it covers the time span of interest, that is, from the early Iron Age to several centuries ago. The types of materials are carbon containing iron-based compositions ranging from wrought irons containing less than $0.05 \% \mathrm{C}$, through steels containing up to $2.1 \% \mathrm{C}$, and cast irons that are defined as over $2.1 \% \mathrm{C}$.

The way carbon dating is used is based on the fact that radioactive carbon, ${ }^{14} \mathrm{C}$, occurs naturally in living matter. Radioactive carbon forms in the atmosphere as a result of cosmic rays creating neutrons that then collide with nitrogen. The ${ }^{14} \mathrm{C}$ that is formed then combines with $\mathrm{O}$ to form $\mathrm{CO}$ and
$\mathrm{CO}_{2}$; these mix with the stable forms of ${ }^{13} \mathrm{C}$ and ${ }^{12} \mathrm{C}$, and living matter absorbs $\mathrm{C}$ that contains this contemporaneous mixture of isotopes. Upon death, ${ }^{14} \mathrm{C}$ is no longer absorbed and proceeds to decay. The rate of decay is at a known rate (a half-life of 5730 years). Nowadays, Accelerator Mass Spectrometry (ASM) can be used to determine the ratio of ${ }^{14} \mathrm{C}$ to ${ }^{12} \mathrm{C}$ because of the different masses of the two isotopes. Thereby the age of the object can be deduced. For iron-based objects, the technique can only be applied if the $\mathrm{C}$ measured in the object reflects the date of manufacture. For example, in the case of Chinese cast irons, in which coal or coke was used to reduce iron ore, carbon dating is excluded because both coal and coke are exhausted of ${ }^{14} \mathrm{C}$. In the case of most other early iron manufacturing, charcoal and wood were used as sources and carbon dating does work.

In contemplating using carbon dating, care must be taken to ensure there is no contamination from other $\mathrm{C}$ sources such as limestone and siderite, shells, or old wood that are depleted in ${ }^{14} \mathrm{C}$, because this can cause articles to appear to be older than they are. The recycling of artefacts can be a complication, and it is always possible that measured dates that are unusual could come from forgeries.

An improved sealed tube combustion method for $\mathrm{C}$ extraction, incorporating simplified sample preparation and reduced sample sizes is described in work by the author and colleagues. ${ }^{55-59}$ Interestingly, it was discovered that, because in many cases rust may still contain the iron carbides from the original steel, as a result of the carbide being thermodynamically more stable than the iron matrix, in at least some cases the carbides in the rust are dating sources. The referenced work ${ }^{55-59}$ documented 72 prior results for iron-based materials; new work by the authors created 20 new results, so by 2003 there was a total of 92 . The range of carbon dated ages for all artefacts started with a standard from modern 


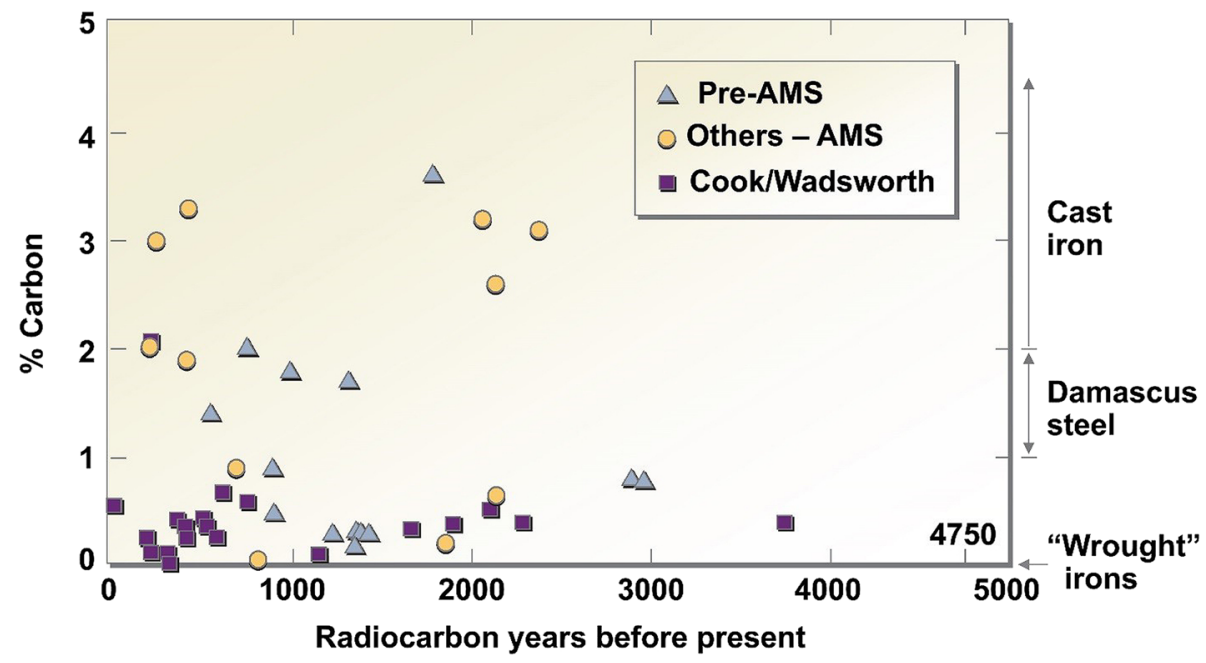

Fig. 12. All the available measurements of carbon dating of iron-based artifacts from 2004 including (1) those measured prior to the use of Accelerator Mass Spectrometry (AMS), i.e. pre-AMS, (2) those measured using AMS, and (3) those by Cook/Wadsworth using a refined method requiring smaller sample sizes. The data are presented with the wt.\% $\mathrm{C}$ plotted versus the experimentally determined age in radiocarbon years before present. The compositions are based on groupings of carbon content starting with wrought iron (very low carbon), then Damascus steels, and cast irons. Obviously, between wrought iron and Damascus steels are the ranges of low, medium, and high carbon compositions.

times, i.e., 1995 A.D. (a modern piece of Japanese folded metal was used). Artefacts starting from 350 B.P. to those from the commonly-accepted start of the Iron Age (4000-5000 B.P.) were examined. Compositions included very low-C wrought irons up to cast irons. Sample sizes were less than $0.05 \mathrm{~g}$ to over $500 \mathrm{~g}$. Conditions of the materials went from clean metal to severely corroded metal and rust. There is no period in Iron Age history that cannot be accessed, in principle, using carbon dating. The data are summarized in Fig. 12.

\section{SUMMARY}

Studies originating with work to develop and commercialize a new type of superplastic steel led to studies of ancient artefacts made by many different methods. Similarities and differences were identified between modern and ancient steel compositions and structures. The range of ancient artefacts and compositions is large, and details remain to be explored. The use of carbon dating was utilized to explore the dates of manufacture of a wide range of compositions, and new insights were found regarding details of this process and its utility. The work is hopefully an example that reveals how exploratory modern studies can intersect with historical materials and lead to an increased understanding of our history, but also be a source of intrigue to draw new researchers into the field.

\section{ACKNOWLEDGEMENTS}

The author is forever indebted to his colleague Oleg D. Sherby who passed away November 9, 2015, age 90. A summary of his career highlights, major contributions to materials science, awards, and some observations about his humor and personality has been prepared for the National Academy of
Engineering Memorial Tributes by Wadsworth and Nix. ${ }^{62}$

\section{REFERENCES}

1. O.D. Sherby and J. Wadsworth, Prog. Mater. Sci. 33, 169 (1989).

2. O.D. Sherby and J. Wadsworth, in Superplasticity in Metals, Ceramics, and Intermetallics, MRS Symp. Proc., vol. 196, ed. M.J. Mayo, M. Kobayashi, and J. Wadsworth (Materials Research Society, Pittsburgh, 1990), p. 3.

3. O.D. Sherby, T.G. Nieh, and J. Wadsworth, Mater. Sci. Forum 243-245, 11 (1997).

4. T.G. Nieh, J. Wadsworth, and O.D. Sherby, Superplasticity in Metals and Ceramics (Cambridge: Cambridge University Press, 1997).

5. J. Wadsworth and O.D. Sherby, Mater. Sci. Technol. 1, 925 (1985).

6. O.D. Sherby and J. Wadsworth, in 1982 ASM Materials Science Seminar, Deformation Processing and Structure, ed. G. Krauss (ASM, Metals Park, 1984), p. 355.

7. O.D. Sherby, T. Oyama, D.W. Kum, B. Walser, and J. Wadsworth, J. Met. 37, 50 (1985).

8. O.D. Sherby and J. Wadsworth, in Encyclopedia of Materials Science and Engineering, First Supplement, ed. R.W. Cahn (Pergamon Press, Oxford, 1988), p. 519.

9. O.D. Sherby and J. Wadsworth, in Encyclopedia of Materials Science and Engineering, First Supplement, ed. R.W. Cahn (Pergamon Press, Oxford, 1988), p. 541.

10. O.D. Sherby, J. Wadsworth, and R.D. Caligiuri, in Metals Handbook, Ninth Edition, Vol. 14: Forming and Forging, Appendix to "Superplastic Sheet Forming," ed. C.H. Hamilton and A.K. Ghosh (ASM, Metals Park, 1988), p. 868.

11. J. Wadsworth and O.D. Sherby, in Thermomechanical Processing and Mechanical Properties of Hypereutectoid Steels and Cast Irons, ed. D.R. Lesuer, C.K Syn, and O.D. Sherby (The Minerals, Metals \& Materials Society, Warrendale, 1997), p. 1.

12. D.R. Lesuer, C.K. Syn, A. Goldberg, J. Wadsworth, and O.D. Sherby, JOM 45, 40 (1993).

13. J. Wadsworth and O.D. Sherby, J. Mech. Work. Technol. 2, 53 (1978).

14. J. Wadsworth and O.D. Sherby, J. Mater. Sci. 13, 2645 (1978). 
15. T. Oyama, J. Wadsworth, M. Korchynsky, and O.D. Sherby, in Strength of Metals and Alloys, ed. P. Haasen, V. Gerold, and G. Kostorz (Pergamon Press, Oxford, 1979), p. 381.

16. O.D. Sherby, D.W. Kum, T. Oyama, and J. Wadsworth,: U.S. Patent 4,769,214, Sept. 6, 1988 .

17. E.S. Kayali, H. Sunada, T. Oyama, J. Wadsworth, and O.D. Sherby, J. Mater. Sci. 14, 2688 (1979).

18. T. Oyama, O.D. Sherby, J. Wadsworth, and B. Walser, Scripta Metall. 18, 799 (1984).

19. O.D. Sherby, T. Oyama, and J. Wadsworth,: U.S. Patent 4,448,613, May 15, 1984.

20. J. Wadsworth and O.D. Sherby, Foundry Manag. Technol. 106, 59 (1978).

21. J. Wadsworth, L.E. Eiselstein, and O.D. Sherby, Mater. Eng. Appl. 1, 143 (1979).

22. O.A. Ruano, J. Wadsworth, and O.D. Sherby, Metall. Trans. 13A, 355 (1982).

23. L.E. Eiselstein, O.A. Ruano, O.D. Sherby, and J. Wadsworth, in Proc. Third Conf. Rapid Solid. Process (National Bureau of Standards, Washington, 1983), p. 246.

24. O.A. Ruano, J. Wadsworth, and O.D. Sherby, U.S. Patent 4,492,671, Jan. 8, 1985.

25. J. Wadsworth, J.H. Lin, and O.D. Sherby, Met. Technol. 8, 190 (1981).

26. O.D. Sherby, M. Carsi, W.J. Kim, D.R. Lesuer, O.A. Ruano, C.K. Syn, E.M. Taleff, and J. Wadsworth, Mater. Sci. Forum 426-432, 11 (2003).

27. H. Sunada, J. Wadsworth, J. Lin, and O.D. Sherby, Mater. Sci. Eng. 38, 35 (1979).

28. O.D. Sherby, J. Wadsworth, D.R. Lesuer, and C.K. Syn, Mater. Trans. 49, 2016 (2008).

29. O.D. Sherby, J. Wadsworth, D.R. Lesuer, and C. K. Syn, in THERMEC 2009, ed. T. Chandra, N. Wanderka, W. Reimers, and M. Ionescu (Trans Tech Publications, Zurich, 2009), p. 160

30. O.D. Sherby, J. Wadsworth, D.R. Lesuer, and C.K. Syn, Mater. Sci. Technol. 28, 471 (2012).

31. J. Wadsworth and O.D. Sherby, Prog. Mater Sci. 25, 35 (1980).

32. J. Wadsworth and O.D. Sherby, Science 218, 328 (1982).

33. O.D. Sherby and J. Wadsworth, Stanf. Eng. 8, 28 (1983).

34. O.D. Sherby and J. Wadsworth, Sci. Am. 252, 112 (1985).

35. O.D. Sherby and J. Wadsworth, Sci. Am. 252, 7 (1985).

36. J. Wadsworth and O.D. Sherby, in Encyclopedia of Materials Science and Engineering, ed. R. Birringer, H. Gleiter, and R. W. Cahn (Pergamon Press, Oxford, 1988), p. 113.

37. O.D. Sherby and J. Wadsworth, SAMPE J. Soc. Adv. Mater. Process Eng. 31, 10 (1995).
38. J. Wadsworth and O.D. Sherby, Mater. Charact. 28, 165 (1992).

39. E.M. Taleff and O.D. Sherby, Mater. Charact. 46, 11 (2001).

40. J. Wadsworth and O.D. Sherby, Mater. Charact. 47, 163 (2001).

41. J. Wadsworth and O.D. Sherby, Mater. Charact. 48, 427 (2002).

42. T. Itoh, M. Tokizane, J. Wadsworth, and O.D. Sherby, $J$. Mech. Work. Technol. 2, 105 (1981).

43. D.W. Kum, T. Oyama, J. Wadsworth, and O.D. Sherby, J. Mech. Phys. Solids 31, 173 (1983).

44. S. Lee, J. Wadsworth, and O.D. Sherby, Res. Mech. 31, 233 (1990).

45. S. Lee, T. Oyama, J. Wadsworth, and O.D. Sherby, Mater. Sci. Eng., A 154, 133 (1992).

46. S. Lee, J. Wadsworth, and O.D. Sherby, J. Eng. Mater. Tech. 114, 278 (1992).

47. O.D. Sherby, J. Wadsworth, R.D. Caligiuri, L.E. Eiselstein, B.C. Snyder, and R.T. Whalen, Scripta Metall. 13, 941 (1979).

48. B.C. Snyder, J. Wadsworth, and O.D. Sherby, Acta Metall. 32,919 (1984).

49. S. Lee, J. Wadsworth, and O.D. Sherby, J. Compos. Mater 25,842 (1991).

50. J. Wadsworth, D. Wha Kum Dong, and O.D. Sherby, Met Prog. 129, 61 (1986).

51. J. Wadsworth and O.D. Sherby, McGraw-Hill Yearbook of Science \& Technology, 6th ed. (New York: McGraw-Hill, 1987), p. 378

52. O.D. Sherby and J. Wadsworth, SAMPE J. Soc. Adv. Mater. Process Eng. 31, 32 (1995).

53. J. Wadsworth and D.R. Lesuer, Mater. Charact. 45, 289 (2000).

54. J. Wadsworth, MRS Bull. 27, 980 (2002).

55. A.C. Cook, J. Wadsworth, and J.R. Southon, Radiocarbon 43,221 (2001)

56. A.C. Cook, J. Wadsworth, J.R. Southon, and N.J. van der Merwe, J. Arch. Sci. 30, 95 (2003)

57. A.C. Cook, J.R. Southon, and J. Wadsworth, JOM 55, 15 (2003).

58. J. Wadsworth, Chin. J. Nat. 28, 125 (2006).

59. J. Wadsworth, Indian J. Hist. Sci. 42, 533 (2007).

60. J. Wadsworth, Mater. Charact. 99, 1 (2015).

61. J. Wadsworth and D.R. Lesuer, Mater. Charact. 45, 315 (2000).

62. J. Wadsworth and W.D. Nix, in National Academy of Engineering of the United States of America: Memorial Tributes, (National Academies Press, Washington, to be published 2017) 